\title{
Can a common bird species be used as a surrogate to draw insights for the conservation of a rare species? A case study from the fragmented Taita Hills, Kenya
}

\author{
Mwangi Githiru, Luc Lens, Leon A. Bennun and Erik Matthysen
}

\begin{abstract}
Sound knowledge of underlying mechanisms is essential for understanding how species respond to habitat fragmentation. Because most threatened species are typically the first ones to suffer local extinctions with forest fragmentation, studying why they fare poorly at the broader landscape scale is difficult. Related, sympatric but common species may be useful surrogates if they can provide insights germane for the conservation of rarer species. We illustrate this using a case study from the highly fragmented Taita Hills forests, south-eastern Kenya, of the Critically Endangered Taita thrush Turdus helleri and the more common white-starred robin Pogonocichla stellata as the surrogate. The responses of the thrush to habitat disturbance were in the same direction as the surrogate robin (e.g. higher fluctuating asymmetry, lower effective population densities and male-biased sex ratios), albeit they were detected sooner and were
\end{abstract}

more severe because of its lower dispersal capacity. The key conservation measures proposed from the surrogate study largely matched those based on an independent evaluation of the thrush data. Additionally, the surrogate provided extra insights into the potential solutions for problems facing the thrush, and provided a base that could be used as a template for restoring the thrush populations in this area. Thus, our findings support the use of surrogate species in the conservation of sympatric related species in fragmented landscapes. We contend that this approach is also applicable for allopatric related species where landscapes are similar, provided that detailed data on population patterns and processes for the surrogate are available.

Keywords Afrotropical, forest loss, fragmentation, Kenya, Pogonocichla stellata, Taita Hills, Turdus helleri.

\section{Introduction}

Studying the impacts of habitat fragmentation on rare species at a broad scale is often difficult because of insufficient sample sizes and restricted distributions, and therefore common species have often been used to guide the conservation of such groups or species (Caro et al., 2005). Surrogates may be used to identify areas that should become the focus for conservation attention in single-species driven conservation (Lambeck, 1997). Alternatively, they may be used where the response of

\footnotetext{
Mwangi Githiru^ (Corresponding author) and Erik Matthysen Laboratory of Animal Ecology, Department of Biology, University of Antwerp,

Universiteitsplein 1, B-2610, Wilrijk, Belgium. E-mail mwangi_githiru@yahoo.co.uk

Luc Lens Terrestrial Ecology Unit, Department of Biology, Ghent University, Ledeganckstraat 35, B-9000, Ghent, Belgium.

Leon A. Bennun BirdLife International, Wellbrook Court, Girton Road, Cambridge CB3 ONA, UK.

${ }^{\star}$ Currently at: Department of Ornithology, National Museums of Kenya, PO Box 40658, 00100 Nairobi, Kenya

Received 7 February 2006. Revision requested 1 August 2006.

Accepted 20 October 2006.
}

one species or population to environmental disturbance is thought to predict the response of another to a similar disturbance (Caro et al., 2005). Here, we use surrogate species in this second sense, where common species are essentially proxies for threatened ones and are not of great conservation interest themselves (Armstrong, 2002).

Except for autecological studies on species under immediate threat, most conservation biology studies have an implicit model species notion, where results from case studies are thought to be relevant for other related and/or sympatric species (Brito \& Fernandez, 2000; Poly, 2003). However, comparable data for both the model and target species are seldom available, which prevents the verification of this assumption. Studies comparing sympatric or congeneric common and rare species (Hodgson, 1993; Cadotte \& LovettDoust, 2002) typically focus not on their applicability as surrogates but on differences between them that could shed light on the causes of rarity (Bevill \& Louda, 1999). It remains unclear whether results from one species can be extrapolated to other ecologically similar species (Green \& Hirons, 1991). Nevertheless, such an evaluation is valuable given the prevalent lack of detailed data 
for threatened species, because rigorous data collection techniques (e.g. manipulative experiments) are typically not possible or desirable with such species (Caro et al., 2005).

However, differences in species' responses to forest fragmentation (Lawton et al., 1998) highlight the need for caution when applying data from one species to infer the population dynamics of, or formulate conservation actions for, another one. Unless the underlying mechanisms by which disturbance affects one species are clear, any general models are unlikely to be useful for crossspecies application (Newton, 1998). Nevertheless, when such mechanisms are known, this information can facilitate drawing logical inferences about problems afflicting species not directly studied. This is particularly pertinent where a target species has been extirpated from a landscape and efforts are being made to establish the factors liable for its extirpation.

We present a case study investigating the usefulness of data from a common (surrogate) species in guiding the conservation of a threatened (target) one. The broad conservation problem was the lack of good understanding of the processes producing the adverse effects of forest loss and fragmentation on critically threatened bird species in the Taita Hills, with a focus on the Taita thrush Turdus helleri. This species is already rare and remnant populations are highly fragmented, making it difficult to conduct broad-scale, long-term, detailed experimental work because of sample size and ethical limitations. Here we examine whether, in the absence of detailed data on the thrush, the surrogate would have been useful in advancing our understanding of the thrush's population dynamics, and hence our ability to formulate conservation interventions. A fundamental strength of this study is that demographic and genetic data are available for the target species, which enables evaluation of the applicability and reliability of this approach. We provide an overview of the key findings, assess the usefulness of studying the common species as a surrogate, and then evaluate the broader application of this approach and circumstances where it could be inappropriate.

\section{Study area}

The Taita Hills forests in south-east Kenya (maximum altitude 2,228 m) are a priority Important Bird Area (Bennun \& Njoroge, 1999). They form the northernmost part of the Eastern Arc forests, a global biodiversity Hotspot (Myers et al., 2000) and an Endemic Bird Area (Stattersfield et al., 1998). Extensive forest loss in the Taita Hills, especially over the last 4 decades, has reduced the indigenous forest to a network of 12 remnant patches scattered across hilltops and ridges
(Fig. 1). Data for the thrush were collected from all 4 patches in which it occurs (Mbololo, Ngangao, Chawia and Yale), and for the robin from 11 of the 12 patches. The main focus of the data presented here will be on the larger fragments Mbololo (c. 180 ha), Ngangao (c. 135 ha), and Chawia (c. 95 ha), the only patches holding sizeable breeding populations of the thrush at the start of our study. Extra data for robins in the small fragments Fururu, Ndiwenyi, Macha, Mwachora and Yale, where the thrush was absent (except for a few individuals in Yale), are also presented. Based on structural qualities of the vegetation (basal tree area per unit area, stem density, canopy cover, shrub density, stratification, and extent of herbaceous ground cover) measured by Wilder et al. (2000) and on plant species' richness and diversity (Githiru et al., 2005a), reduction in fragment size was associated with increased habitat disturbance. This was reflected in smaller fragments showing lesser structural diversity and lower plant species richness and diversity. Chawia was undergoing greater degradation from the human population living around it than the rest of the fragments at the time of this study (M. Githiru, pers. obs.).

\section{Methods}

The conservation target species, the Taita thrush Turdus helleri (Family Turdidae), is categorized as Critically Endangered on the IUCN Red List (BirdLife International, 2004; IUCN, 2006). It is endemic to the Taita Hills, strictly forest dependent, shy, and skulking, keeping to dense thickets and forest undergrowth without venturing into secondary forest, scrub or cultivation (Bowie et al., 2005). It usually forages by digging in forest floor leaf litter using its strong bill, occasionally trailing ants and feeding on fruits. From a candidate set of eight bird species in these forests (two greenbul species Andropadus milanjensis and Phyllastrephus cabanisi, a robin Pogonocichla stellata, a thrush Zoothera gurneyi otomitra, a sunbird Nectarinia olivacea, an apalis Apalis fuscigularis, a white-eye Zosterops silvanus and a warbler Phylloscopus ruficapillus; species details in Brooks et al., 1998) we selected the white-starred robin Pogonocichla stellata as the most appropriate surrogate based on five broad characteristics (Table 1). These eight species constitute over $92 \%$ of all mist net captures in this study area, and hence are representative of the low and mid canopy bird community (Lens et al., 1999). The white-starred robin is a forest-dependent bird resident in montane forests of eastern to southern Africa (Keith et al., 1992). It forages at all levels in the forest, most frequently in the undergrowth and at ant trails, but also tosses leaf litter, gleans foliage, makes aerial sallies to capture flying prey 


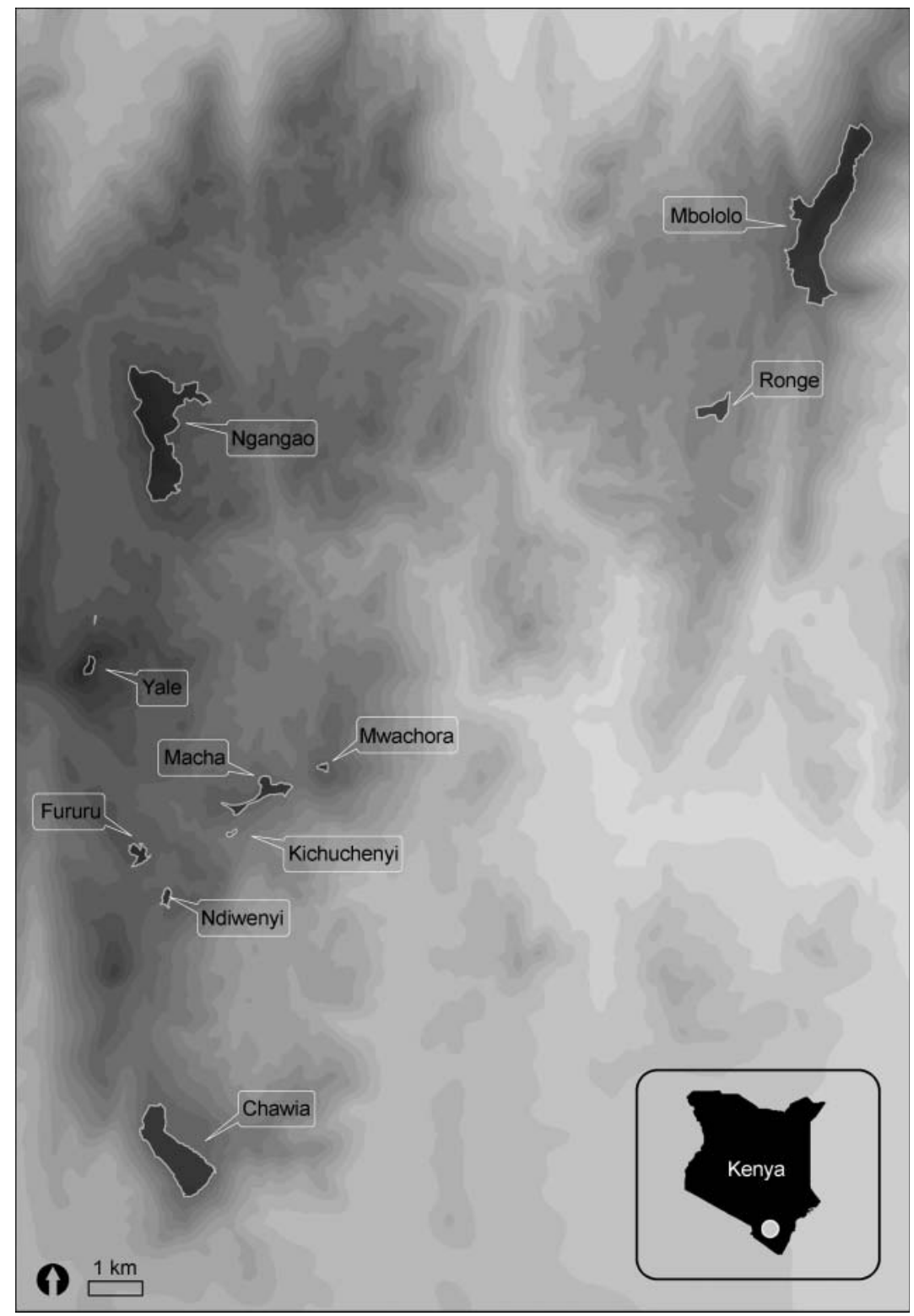

Fig. 1 The Taita Hills, with the forest fragments (see text for details) shaded black; altitudinal contours are in greyscale from lowest (light grey) to highest (dark grey). The inset shows the location of the Taita Hills in Kenya. and ascends into the canopy for small fruits when available, e.g. Rhus sp. (Keith et al., 1992).

Between 1996 and 2004 birds were captured using mist nets. Standard biometric measurements were taken from all birds captured, including multiple measures of the tarsi for assessing fluctuating asymmetry, and a blood sample. Capture-recapture data were used to estimate population densities, survival and dispersal probabilities (details in Githiru \& Lens, 2006a,b). Selected individuals were fitted with radio transmitters for intensive tracking to obtain estimates of territory size (Githiru et al., in press). Sex determination was from a combination of molecular and morphological techniques (mainly using wing length; Lens et al., 1998; Githiru \& Lens, 2006a).
Species-specific levels of stress tolerance were estimated from levels of fluctuating asymmetry in tarsus length (based on repeated measurements). In addition to birds measured in the field, museum specimens from the same populations, collected prior to the major forest losses, were also measured (details in Lens et al., 1999; Lens et al., 2002). Blood samples were genotyped using sets of seven highly variable microsatellite primers for each species. They were used to estimate mean number of alleles per locus (MNA), effective population sizes $\left(\mathrm{N}_{\mathrm{e}}\right)$, observed and expected heterozygosities $\left(\mathrm{H}_{\mathrm{obs}}\right.$ and $\mathrm{H}_{\text {exp }}$ ), and genetic differentiation, migration-drift and mutation-drift equilibria (details in Galbusera et al., 2000; Galbusera et al., 2004). Dispersal was estimated using three methods: (1) dispersal probability using 
Table 1 Potential surrogate bird species in the Taita Hills forests for the Critically Endangered Taita thrush Turdus helleri. The characteristics are ranked from 0 to 3, i.e. worst to best in terms of being surrogates. For ecological similarity (all get at least 1 for living in the same area) and phenology these ranks indicate how each species compares to the thrush; distribution and commonness are relative to each other, and ethics considers the species' IUCN Red List (IUCN, 2006) category. The species chosen as the surrogate, the white-starred robin, is in bold.

\begin{tabular}{|c|c|c|c|c|c|}
\hline Species & $\begin{array}{l}\text { Ecological } \\
\text { similarity }\end{array}$ & $\begin{array}{l}\text { Phenological } \\
\text { relatedness }\end{array}$ & $\begin{array}{l}\text { Distribution } \\
\text { (in landscape) }\end{array}$ & $\begin{array}{l}\text { Commonness } \\
\text { (in mist nets) }\end{array}$ & Ethical issues \\
\hline $\begin{array}{l}\text { Phyllastrephus cabanisi } \\
\text { Cabanis's greenbul }\end{array}$ & 1 & 0 & 2 & 2 & 3 \\
\hline $\begin{array}{l}\text { Andropadus milanjensis } \\
\text { Stripe-cheeked greenbul }\end{array}$ & 1 & 0 & 3 & 2 & 3 \\
\hline Nectarinia olivacea Olive sunbird & 1 & 0 & 3 & 3 & 3 \\
\hline $\begin{array}{l}\text { Zosterops silvanus Montane } \\
\text { white-eye }\end{array}$ & 1 & 0 & 3 & 2 & 3 \\
\hline $\begin{array}{l}\text { Phylloscopus ruficapillus } \\
\text { Yellow-throated woodland } \\
\text { warbler }\end{array}$ & 1 & 0 & 1 & 2 & 3 \\
\hline Apalis fuscigularis Taita apalis* & 1 & 0 & 1 & 1 & 0 \\
\hline $\begin{array}{l}\text { Zoothera gurneyi } \\
\text { Orange-ground thrush }\end{array}$ & 3 & 3 & 1 & 1 & 3 \\
\hline $\begin{array}{l}\text { Pogonocichla stellata } \\
\text { White-starred robin }\end{array}$ & 3 & 3 & 3 & 3 & 3 \\
\hline
\end{tabular}

*Critically Endangered (IUCN, 2006)

capture-recapture data, (2) genetic data used to estimate current gene flow and (3) the coalescence theory to estimate the historical number of migrants (details in Galbusera et al., 2000; Lens et al., 2002; Galbusera et al., 2004).

\section{Results}

Population densities of the robin were similar in Mbololo, Ngangao and the small fragments, but $c$. three times lower in Chawia (Table 2). However, densities of the thrush in Ngangao and Chawia were three and 12 times lower, respectively, than in Mbololo. Although there was minimal variation in territory size and sex ratios of the robin between fragments, the thrush exhibited an increase in territory size and a drastic decline in the proportion of the population that was female as habitat quality deteriorated (Table 2).

With increasing habitat disturbance both species had increasing levels of fluctuating asymmetry but this was more accentuated for the thrush, with the value in Chawia, the most disturbed fragment, seven times higher than that in Mbololo, the least disturbed fragment. The corresponding estimate for the robin was only 3.5 times higher (Lens et al., 1999; Lens \& Van Dongen, 2000). Comparing the ancient to contemporary values of fluctuating asymmetry for each fragment separately, we did not find significant differences for the robin, whereas the thrush showed a significant increase in fluctuating asymmetry, but only in Chawia (Lens et al., 1999; Lens \& Van Dongen, 2000).
The robin had almost equal $\mathrm{N}_{\mathrm{e}}$ values in Mbololo and Ngangao, but $\mathrm{N}_{\mathrm{e}}$ was three times lower in Chawia; that of the thrush was five times lower in Ngangao than in Mbololo, and five times lower in Chawia than in Ngangao. However, the MNA data reveal no allele losses in Chawia for the robin (as would be expected with the low $\mathrm{N}_{\mathrm{e}}$ ), whereas losses are revealed for the thrush (Galbusera et al., 2000; Galbusera et al., 2004). This was probably due to a combination of the lower dispersal rates and more drastic reduction in $\mathrm{N}_{\mathrm{e}}$ of the thrush. The assertion of lower dispersal is supported by the equilibrium analyses that show that, whereas the robin populations were at both migration and mutation-drift equilibriums, the thrush population in Chawia had suffered a recent bottleneck (Galbusera et al., 2000; Galbusera et al., 2004). Finally, the robin only had significant differentiation between the Mbololo and other populations, whereas the thrush subpopulations in Mbololo, Ngangao and Chawia were all different in this respect.

Capture-recapture data revealed that the robin's monthly probability of dispersal was substantially higher than the thrush's (0.0019 versus 0.00013 , respectively; Lens et al. 2002b). Estimates of current dispersal were six and three migrants per generation for the robin and thrush, respectively. Historical dispersal revealed a mean of 2.9 migrants per generation for the robin, and 1.7 for the thrush (Galbusera et al., 2000; Galbusera et al., 2004). Overall, the robin is a better disperser than the thrush.

Larger sample sizes of the robin, together with its wider distribution across the landscape, facilitated more in depth analyses on population growth rates, survival 
Table 2 Population density, effective population size $\left(\mathrm{N}_{\mathrm{e}}\right)$, mean territory size and percentage of females $( \pm$ SE) of the white-starred robin and the Taita thrush in the three large fragments Mbololo (180 ha), Ngangao (135 ha) and Chawia ( $95 \mathrm{ha})$, and in the small fragments ( $<10$ ha) for the robin. Information from Lens et al. (1998), Galbusera et al. (2000), Githiru (2003), Galbusera et al. (2004) and Githiru \& Lens (2006a).

\begin{tabular}{|c|c|c|c|c|c|c|c|}
\hline \multirow[b]{2}{*}{ Parameter } & \multicolumn{4}{|c|}{ White-starred robin } & \multicolumn{3}{|l|}{ Taita thrush } \\
\hline & Mbololo & Ngangao & Chawia & Small fragments & Mbololo & Ngangao & Chawia \\
\hline Density $\left(\mathrm{ha}^{-1}\right)$ & 6 & 6 & 2 & 5 & 6 & 2 & 0.5 \\
\hline $\mathrm{N}_{\mathrm{e}}$ & 60 & 49 & 15 & & 75 & 15 & 3 \\
\hline Territory size (ha) & Not studied & $0.71 \pm 0.10$ & $0.71 \pm 0.07$ & $0.83 \pm 0.26$ & $0.55 \pm 0.09$ & $0.63 \pm 0.14$ & $0.91 \pm 0.24$ \\
\hline$\%$ females & Not studied & $31.8 \pm 3.5$ & $34.8 \pm 4.2$ & $43.3 \pm 4.2$ & 50 & 39 & 10 \\
\hline
\end{tabular}

and turnover rates, assessment of variation in sex-ratios amongst age classes, estimation of productivity using juvenile:adult ratios and probability of nest survival, and removal experiments for the assessment of social structure based on presence/absence of floaters. The data (Table 3) indicate that all the subpopulations were stable despite the productivity in Chawia being significantly lower than that of Ngangao and the small fragments (Githiru \& Lens, 2006a). Although survival probabilities were similar amongst the fragments, turnover rate of individuals was lower in Ngangao compared to the rest (Githiru \& Lens, 2006b). Together with productivity and dispersal data, this indicates a hierarchical spatial structure, with a source-sink system at a wider scale (where Ngangao and the small fragments are probably source populations and Chawia is a sink), and a smaller-scale metapopulation system for the small fragments (Githiru, 2003; Githiru \& Lens, 2004). Populations in the small fragments overcame the potential negative effects of their small sizes by operating as a metapopulation with high inter-patch dispersal. Finally, the presence of male and female floaters in Ngangao and their absence in Chawia (Githiru et al., 2006) confirmed that Ngangao was a better quality fragment for the robins (Smith \& Arcese, 1989; Stutchbury \& Morton, 2001).

\section{Discussion}

\section{Direct comparison}

The data indicate that in spite of the problems the surrogate suffered in Chawia the population size there was relatively stable, suggestive of a sink population where dispersal is sufficient to offset demographic shortfalls (Githiru \& Lens, 2004). This conclusion is supported by the genetic data, which, despite small $\mathrm{N}_{\mathrm{e}}$, reveal high MNA and heterozygosity levels and both migration-drift and mutation-drift equilibria (Galbusera et al., 2004). Given the observed dispersal patterns and high genetic relatedness between Chawia and the populations in most of the small fragments (Galbusera et al., 2004), it is apparent that the robin populations in the small patches play a critical role as source populations, stepping stones, and to a certain extent, as genetic banks (Turner \& Corlett, 1996).

It is therefore likely that regulation of the robin's population dynamics is by productivity and mortality levels in Chawia, and dispersal from neighbouring fragments to offset this deficit. For the thrush, the extremely skewed sex ratio (10\% females) coupled with low population density in Chawia could have drastically reduced the productivity of this population. Because of the species' low dispersal capacity there

Table 3 Extra parameters (mean $\pm \mathrm{SE}$ ) calculated for the white-starred robin from the subpopulations in Ngangao, Chawia, and the small fragments. Sources: Githiru (2003), Githiru \& Lens (2004), Githiru et al. (2005b), Githiru \& Lens (2006a,b).

\begin{tabular}{|c|c|c|c|}
\hline Parameter & Ngangao & Chawia & Small fragments \\
\hline Population growth rate & $0.96 \pm 0.052$ & $1.07 \pm 0.059$ & $1.06 \pm 0.059$ \\
\hline \multicolumn{4}{|l|}{ Productivity } \\
\hline Juvenile to adult ratio & 0.59 & 0.20 & 0.80 \\
\hline Probability of nest survival & $0.43 \pm 0.151$ & $0.13 \pm 0.073$ & $0.45 \pm 0.181$ \\
\hline \multicolumn{4}{|l|}{ Social structure } \\
\hline $\begin{array}{l}\text { No. of floaters per territory } \\
\text { Survival }\end{array}$ & $1-3$ & None & Not studied \\
\hline Annual survival ơ & $0.83 \pm 0.258$ & $0.83 \pm 0.258$ & $0.83 \pm 0.258$ \\
\hline ९ & $0.43 \pm 0.212$ & $0.43 \pm 0.212$ & $0.43 \pm 0.212$ \\
\hline Turnover o’ & $0.95 \pm 0.045$ & $0.87 \pm 0.064$ & $0.87 \pm 0.054$ \\
\hline ф & $0.83 \pm 0.062$ & $0.64 \pm 0.13$ & $0.66 \pm 0.087$ \\
\hline Spatial structure & Source & Sink & Source \& metapopulation \\
\hline
\end{tabular}


was little likelihood that dispersal would have a similar demographic rescue-effect as the robin. Besides this demographic consequence, insufficient dispersal has genetic ramifications, including a reduction in gene flow, bottlenecks from inbreeding, and loss of genetic variation (Galbusera et al., 2000). The absence of thrush populations in most of the small fragments verifies the poor metapopulation viability of this species. Therefore, improving the habitat quality within the landscape matrix (matrix here refers to the human-dominated landscape separating the indigenous forest fragments, where small-scale agricultural holdings predominate) to encourage movements between fragments, as well as increasing the number of small subpopulations, is crucial for ensuring the long-term persistence of the thrush. However, in order to reap the benefits of such improvements, it is essential that core populations (currently Ngangao and Mbololo) keep producing dispersers.

Overall, the thrush is more sensitive to habitat loss, particularly as habitat quality declines, and is affected sooner by fragmentation than the robin. However, the effects of forest loss and fragmentation were largely in the same direction for the two species, which is an important requirement for using any species as a substitute (Caro et al., 2005). The thrush's response to forest disturbance is generally ahead of the robin's, such that while Mbololo is clearly the best habitat for both species, Ngangao is almost equally good for the robin but the thrush has already started showing signs of population problems there. In summary, given a habitat quality gradient, the negative effects of habitat disturbance are observed earlier in the thrush than in the robin.

\section{Prognostic application}

Because the responses of the robin to forest fragmentation and degradation are in the same direction as those of the thrush, it is valid to project findings from the robin to the thrush. Compared to the study of the thrush, that of the robin had three additional advantages: broader scale, experimental removals, and larger sample sizes. Firstly, the ability to work across the entire landscape provided a more precise picture of the spatial structure of the population, which indicates the required scale of conservation (Opdam \& Wiens, 2002). For example, although the need to improve the sink habitat (i.e. Chawia) is clear from both studies, the surrogate work indicates nest predation is probably causing the low productivity. Between patches, improving the ability to disperse through the matrix amongst the small fragments, and between the small fragments and Chawia, is crucial (see also Laurance et al., 2002, for the importance of the matrix). Thus, the thrush requires even more matrix improvement because of its lower dispersal capacity. The small fragments also require within-patch habitat improvement and enlargement in order to support small pockets of thrush populations as well as acting as stepping-stones for dispersing individuals. Thus, although these are basic conservation biology principles, the surrogate study endorsed their relevance in this landscape, and revealed the key factors that need urgent attention.

Secondly, the removal experiment revealed different robin social structures in different quality fragments (Githiru et al., 2006). In addition to having immediate ramifications for the population's productivity, floaters may be important for the management of the thrush should translocations be attempted (Galbusera et al., 2000) because they represent the best targets for translocation (Komdeur, 1992). The better quality fragment, Ngangao, had floaters of both sexes of robin, but there were no floaters in the more disturbed fragment, Chawia (Table 3). It is likely that the thrush would show a similar pattern but, as indicated earlier, the thrush would be a step ahead of the robin. Thus, whereas Ngangao has floaters for the robin, only Mbololo is likely to have floaters for the thrush. Consequently, care needs to be taken if translocations are to be undertaken as a conservation strategy for the thrush; individuals should not be removed from Ngangao unless further research shows there are floaters there. If translocations are to be attempted without the benefit of further research, knowledge of the surrogate indicates they should only be obtained from Mbololo.

Thirdly, ample data for different age groups revealed that sex ratios were similarly skewed across age groups for the robin (Galbusera et al., 2004). Because the thrush showed either similar or even more male-biased sex ratios, and there were anecdotal signs of female predation during incubation (M. Githiru, pers. obs.), it is likely it faces analogous problems to the robin. For the robin, the skewed sex ratio had detrimental ramifications for productivity in fragment Chawia (Githiru \& Lens, 2006a), with several territories having unmated males (Githiru et al., 2006). This was not observed in the other fragments, which had higher population densities. For the thrush the low population densities in Ngangao and Chawia, coupled with the more male-biased sex ratios in these patches compared to Mbololo (Table 2), suggest the presence of unmated territorial males in these patches. This would diminish the productivity of the populations, especially in Chawia, and could provide a case for female translocations if conditions were improved. As a caveat, we emphasize the need for habitat improvement before undertaking any translocations of female thrushes.

In summary, the test for the value of a surrogate species is if it independently leads to conservation 
measures that would benefit the target species. Clearly, even in the absence of detailed ecological and/or population information for the thrush, the conservation implications from the robin study could be extrapolated to benefit the thrush. Insights derived from the landscape-scale work of the robin are helpful for improving our understanding of the potential underlying causes of the problems facing the thrush. In particular, they provide clues about the nature of the spatial structure of the thrush populations before fragmentation as a template to guide conservation planning.

\section{Broader applicability of the surrogacy approach and conclusions}

Despite many studies implicitly invoking the model/ surrogate argument, we could not find any published work explicitly addressing the use of surrogate species in conservation from which we could draw specific comparisons. Although our study was confined to related and sympatric surrogate species, if detailed demographic (and preferably genetic) data are available for the surrogate, together with basic natural history information for the target species, we believe this approach can also be applied to related species living in separate but similar habitats. By making more considered recommendations this would improve conservation planning where appropriate data are unavailable. However, there are situations where this approach would be difficult to apply, either because of problems with design or lack of appropriate data. Obviously, when basic natural history information is not available for the target species, extrapolating any findings from another species will be tricky, at best. Fortunately, this is not likely to be a problem for many bird species. Extrapolating findings from entirely unrelated species, such as different guilds in birds, is more difficult. Working with entirely different taxa, such as birds and mammals or any other species, is most problematic. Equally, perhaps most challenging, without a good understanding of the mechanisms driving patterns observed in the surrogate, it would not be possible to use this information to understand what could be happening to another species. Generally, as species become increasingly unrelated, habitats more different, and data restricted to patterns rather than processes, the application of the surrogate species concept becomes more and more tenuous.

\section{Acknowledgements}

We thank staff of the Ornithology Department, National Museums of Kenya, our field workers B. Amakobe,
M. Chovu, D. Gitau, D. Samba, K. Ndang'ang'a and T. Imboma, S. Van Dongen, P. Galbusera, T. Schenck and T. van de Casteele for laboratory work and data analyses at the University of Antwerp, H. Mathere for map preparation, and T. Caro and an anonymous reviewer for comments on an earlier draft. Research work was funded by VLIR and the Fund for Scientific Research Flanders (FWO-Flanders, Belgium; current project G.0210.04), the University of Antwerp, the Rhodes Trust, and the James Lynch Conservation Biology Fund. During the writing of this paper, MG was supported by a Marie Curie Incoming International Fellowship.

\section{References}

Armstrong, D.P. (2002) Focal and surrogate species: getting the language right. Conservation Biology, 16, 285-286.

Bennun, L.A. \& Njoroge, P. (1999) Important Bird Areas in Kenya. EANHS, Nairobi, Kenya.

Bevill, R.L. \& Louda, S.M. (1999) Comparisons of related rare and common species in the study of plant rarity. Conservation Biology, 13, 493-498.

BirdLife International (2004) Threatened Birds of the World. CDROM, BirdLife International, Cambridge, UK.

Bowie, R.C.K., Voelker, G., Fjeldså, J., Lens, L., Hackett, S.J. \& Crowe, T.M. (2005) Systematics of the olive thrush Turdus olivaceus species complex with reference to the taxonomic status of the endangered Taita thrush T. helleri. Journal of Avian Biology, 36, 391-404.

Brito, D. \& Fernandez, F.A.S. (2000) Metapopulation viability of the marsupial Micoureus demerarae in small Atlantic forest fragments in south-eastern Brazil. Animal Conservation, 3, 201-209.

Brooks, T., Lens, L., Barnes, J., Kihuria, J.K. \& Wilder, C. (1998) The conservation status of the forest birds of the Taita Hills, Kenya. Bird Conservation International, 8, 119-139.

Cadotte, M.W. \& Lovett-Doust, J. (2002) Ecological and taxonomical differences between rare and common plants of southwestern Ontario. Ecoscience, 9, 397-406.

Caro, T., Eadie, J. \& Sih, A. (2005) Use of substitute species in conservation biology. Conservation Biology, 19, 1821-1826.

Galbusera, P., Githiru, M., Lens, L. \& Matthysen, E. (2004) Genetic equilibrium despite habitat fragmentation in an Afrotropical bird. Molecular Ecology, 13, 1409-1421.

Galbusera, P., Lens, L., Schenck, T., Waiyaki, E. \& Matthysen, E. (2000) Genetic variability and gene flow in the globally critically-endangered Taita thrush. Conservation Genetics, 1, 45-55.

Githiru, M. (2003) Endemic forest birds of the Taita Hills: using a model species to understand the effects of habitat fragmentation on small populations. DPhil thesis, University of Oxford, Oxford, UK.

Githiru, M., Bennun, L., Lens, L. \& Ogol, C.P.K.O. (2005a) Spatial and temporal variation in fruit and fruit-eating birds in the Taita Hills, southeast Kenya. Ostrich, 76, 37-44.

Githiru, M. \& Lens, L. (2004) Using scientific evidence to guide the conservation of a highly fragmented and threatened Afrotropical forest. Oryx, 38, 404-409.

Githiru, M. \& Lens, L. (2006a) Demography of an Afrotropical passerine in a highly fragmented and threatened forest landscape. Animal Conservation, 9, 21-27. 
Githiru, M. \& Lens, L. (2006b) Survival and turnover rates of an Afrotropical songbird living in a fragmented landscape. Biodiversity and Conservation, 15, 3315-3327.

Githiru, M., Lens, L. \& Bennun, L. (in press) Ranging behaviour and habitat use by an afrotropical songbird in a fragmented landscape. African Journal of Ecology.

Githiru, M., Lens, L., Bennun, L. \& Perrins, C.M. (2006) Experimental evidence of 'floaters' in two isolated populations of an Afrotropical forest bird. Ostrich, 77, 28-35. Githiru, M., Lens, L. \& Cresswell, W. (2005b) Nest predation in a fragmented Afrotropical forest: evidence from natural and artificial nests. Biological Conservation, 123, 189-196.

Green, R.E. \& Hirons, G.J.M. (1991) The relevance of population studies to the conservation of threatened birds. In Bird Population Studies: Relevance to Conservation and Management (eds C.M. Perrins, J.-D. Lebreton \& G.J.M. Hirons), pp. 594-621. Oxford University Press, New York, USA.

Hodgson, J.G. (1993) Commonness and rarity in British butterflies. Journal of Applied Ecology, 30, 407-427.

IUCN (2006) 2006 IUCN Red List of Threatened Species. IUCN, Gland, Switzerland [http://www.redlist.org, accessed 2 March 2007].

Keith, S., Urban, E.K. \& Fry, C.H. (eds) (1992) The Birds of Africa. Academic Press, London, UK.

Komdeur, J. (1992) Importance of habitat saturation and territory quality for evolution of cooperative breeding in the Seychelles warbler. Nature, 358, 493-495.

Lambeck, R.J. (1997) Focal species: a multi-species umbrella for nature conservation. Conservation Biology, 11, 849-856.

Laurance, W.F., Lovejoy, T.E., Vasconelos, H.L., Bruna, E.M., Didham, R.K., Stouffer, P.C., Gascon, C., Bierregaard, R.O.J., Laurance, S.G. \& Sampiao, E. (2002) Ecosystem decay of Amazonian forest fragments: a 22-year investigation. Conservation Biology, 16, 605-618.

Lawton, J.H., Bignell, D.E., Bolton, B., Bloemers, G.F., Eggleton, P., Hammond, P.M., Hodda, M., Holt, R.D., Larsen, T.B., Mawdsley, N.A., Stork, N.E., Srivastava, D.S. \& Watt, A.D. (1998) Biodiversity inventories, indicator taxa and effects of habitat modification in tropical forest. Nature, 391, 72-76.

Lens, L., Galbusera, P., Brooks, T., Waiyaki, E. \& Schenck, T. (1998) Highly skewed sex ratios in the critically endangered Taita thrush as revealed by CHD genes. Biodiversity and Conservation, 7, 869-873.

Lens, L., Van Dongen, S., Norris, K., Githiru, M. \& Matthysen, E. (2002) Avian persistence in fragmented rainforest. Science, 298, 1236-1238.

Lens, L., Van Dongen, S. \& Wilder, C. (1999) Fluctuating asymmetry increases with habitat disturbance in seven bird species of a fragmented afrotropical forest. Proceedings of the Royal Society of London B, 266, 1241-1246.
Myers, N., Mittermeier, R.A., Mittermeier, C.G., da Fonseca, G.A.B. \& Kent, J. (2000) Biodiversity hotspots for conservation priorities. Nature, 403, 853-858.

Newton, I. (1998) Population Limitation in Birds. Academic Press, San Diego, USA.

Opdam, P. \& Wiens, J.A. (2002) Fragmentation, habitat loss and landscape management. In Conserving Bird Biodiversity: General Principles and their Application (eds K. Norris \& D.J. Pain), pp. 202-223. Cambridge University Press, Cambridge, UK.

Poly, W.J. (2003) Design and evaluation of a translocation strategy for the fringed darter (Etheostoma crossopterum) in Illinois. Biological Conservation, 113, 13-22.

Smith, J.N.M. \& Arcese, P. (1989) How fit are floaters? Consequences of alternative territorial behaviors in a nonmigratory sparrow. American Naturalist, 133, 830-845.

Stattersfield, A.J., Crosby, M.J., Long, A.J. \& Wege, D.C. (1998) Endemic Bird Areas of the World: Priorities for Biodiversity Conservation. BirdLife International, Cambridge, UK.

Stutchbury, B.J. \& Morton, E.S. (2001) Behavioral Ecology of Tropical Birds. Academic Press, San Diego, USA.

Turner, I.M. \& Corlett, R.T. (1996) The conservation value of small, isolated fragments of lowland tropical rain forest. Trends of Ecology and Evolution, 11, 330-333.

Wilder, C.M., Brooks, T.M. \& Lens, L. (2000) Vegetation structure and composition of the Taita Hills forests. Journal of the East African Natural History Society, 87, 181-187.

\section{Biographical sketches}

Mwangi Githiru studies processes by which forest fragmentation affects species and their interactions. He has also initiated small-scale education initiatives in schools, seeking to develop environmental awareness, and is interested in incorporating conservation activities and principles into rural development projects.

Luc Lens' research focuses on population demography and social organization, and on the development of phenotypic markers of environmental and genetic stress, using temperate and tropical songbirds, butterflies and spiders.

Leon Bennun has worked extensively on the conservation biology of East African birds. He is particularly interested in how science can be used for better conservation decisionmaking.

Erik Matthysen's research focuses on dispersal and population structure in populations of songbirds, butterflies and small mammals, including behaviour, population genetics, demography and landscape connectivity. 